\title{
Teste de tetrazólio em sementes de timbaúba
}

\section{Tetrazolium test in timbaúba seeds}

\author{
Narjara Walessa Nogueira ${ }^{1 *}$; Salvador Barros Torres²; \\ Rômulo Magno Oliveira de Freitas ${ }^{1}$
}

\begin{abstract}
Resumo
O teste de tetrazólio tem se mostrado uma alternativa promissora na determinação da viabilidade e do vigor da semente de espécies florestais pela qualidade e rapidez na obtenção dos dados. Dessa forma, o presente trabalho foi desenvolvido objetivando-se padronizar a metodologia de condução do teste de tetrazólio para a avaliação da qualidade fisiológica de lotes de sementes de timbaúba. Para avaliar qualidade fisiológica das sementes os quatro lotes foram submetidos às seguintes determinações: teor de água, teste de germinação, primeira contagem e velocidade de germinação. Quatro repetições, com 25 sementes de cada lote, foram submersas em solução de tetrazólio nas concentrações de 0,$1 ; 0,07$ e $0,050 \%$, e mantidas no escuro a $35^{\circ} \mathrm{C}$, por períodos de $1 ; 3$ e 6 horas. Decorridos os períodos de coloração, as sementes foram lavadas, seccionadas longitudinalmente entre os cotilédones e classificados em viáveis e não viáveis. A exposição das sementes pelos períodos de uma hora e de seis horas mostrouse inadequada para a condução do teste de tetrazólio, uma vez que não promoveu a coloração adequada a interpretação dos resultados. O teste de tetrazólio é uma alternativa viável para a avaliação de vigor de lotes de timbaúba. Para condução do teste recomenda-se a escarificação das sementes seguida de embebição em água por 24 horas e retirada do tegumento, com posterior imersão das sementes por três horas em solução de tetrazólio de $0,075 \%$, a $35^{\circ} \mathrm{C}$.
\end{abstract}

Palavras-chave: Enterolobium contortisiliquum, potencial fisiológico, viabilidade

\begin{abstract}
The tetrazolium test has shown itself to be a promising alternative in determining the viability and vigor of seeds of forest species by the quality and speed of data collection. Thus, this paper was developed with the goal of standardizing the methodology for conducting the tetrazolium test for assessing the physiological quality of seed lots Timbaúba. To evaluate the physiological quality of seeds the four lots were subjected to the following determinations: water content, germination, first count and speed germination. Four replicates of 25 seeds from each batch were submerged in tetrazolium solution and kept in the dark at $35^{\circ} \mathrm{C}$ for periods of 1,3 and 6 hours under concentrations of $0.1,0.075$ and $0.050 \%$. After the staining periods, the seeds were washed, split lengthwise between the cotyledon and ranked in viable and not viable. Seed exposure for periods of one hour and six hours has proved inadequate for driving the tetrazolium test since not promoted the proper interpretation of staining results. The tetrazolium test is a viable alternative for the evaluation of existing lots of Timbaúba. To conduct the test recommended scarification followed by soaking the seeds in water for 24 hours and coat removal, with subsequent soaking of seeds for three hours in tetrazolium solution of $0.075 \%$ at $35^{\circ} \mathrm{C}$.
\end{abstract}

Key words: Enterolobium contortisiliquum, physiological potential, viability

\footnotetext{
${ }^{1}$ Eng $^{\text {as }}$ Agr $^{{ }^{a} \mathrm{~s}}$, Discentes de Doutorado em Fitotecnia, Universidade Federal Rural do Semi-Árido, UFERSA, Mossoró, RN. E-mail: narjarawalessa@yahoo.com.br; romulomagno_23@hotmail.com.br

${ }^{2}$ Eng $^{\mathrm{o}}$ Agr $^{\circ}$, Dr. em Fitotecnia. Pesquisador, Empresa de Pesquisa Agropecuária do Rio Grande do Norte, EMPARN. Prof. Colaborador, UFERSA, Mossoró, RN. E-mail: sbtorres@ufersa.edu.br

* Autor para correspondência
} 


\section{Introdução}

A timbaúba (Enterolobium contortisiliquum (Vell.) Morong) é uma árvore nativa, pertencente à família Fabaceae, que ocorre em várias regiões do Brasil (LORENZI, 2002). Possui vários nomes vulgares, dentre eles "timbaúba", "orelha-denegro", "orelha-de-macaco", "timbó" ou "tamboril". Distribui-se pelos estados do Pará, Maranhão e Piauí até o Mato Grosso do Sul e Rio Grande do Sul, como também, nas florestas pluviais e semidecíduas (COSTA et al., 2009). Sua madeira é considerada de durabilidade mediana, podendo ser empregada na fabricação de canoas, móveis, portas, caixotaria em geral e construção civil (LORENZI, 2002; COSTA et al., 2012).

É uma espécie muito usada em áreas de reflorestamento, principalmente em áreas degradadas, por se desenvolver rapidamente e em vários tipos de solo (LIMA; OLIVEIRA; RODRIGUES, 2009). Entretanto, pouco se sabe sobre a germinação da timbaúba, fator este, que em muitos casos leva ao insucesso daqueles que pretendem produzir mudas desta espécie (ARAÚJO; PAIVA SOBRINHO, 2011).

A avaliação da viabilidade das sementes é rotineiramente avaliada pelo teste de germinação. Este, conduzido sob condições altamente favoráveis de temperatura, umidade e substrato, viabilizando assim, o máximo potencial para germinação e, muitas vezes, não refletindo o comportamento das espécies em campo, como também, não detectando estádios avançados de deterioração (LARRÉ; MORAES; LOPES, 2009). Além disso, requer um período relativamente longo para a obtenção dos resultados, sendo este um grande entrave que limita a tomada de decisão durante o controle de qualidade das sementes (COSTA; SANTOS, 2010). Com sementes de timbaúba, Alexandre et al. (2009) verificaram que o tempo médio de germinação variou de 5 a 9 dias. Por essa razão, necessita-se desenvolver e aperfeiçoar testes rápidos e confiáveis que ofereçam a caracterização do potencial fisiológico das sementes.
Nesse sentido, o teste de tetrazólio tem se mostrado uma alternativa promissora na determinação da viabilidade e do vigor da semente de várias espécies florestais pela qualidade e rapidez na obtenção dos resultados. Neste teste, as sementes permanecem em contato com uma solução incolor de cloreto de tetrazólio (2,3,5 trifenil cloreto de tetrazólio), que é absorvida pelos tecidos vivos da semente. Nos tecidos que apresentam atividades respiratória e metabólica normais, as enzimas do grupo das desidrogenages liberam íons hidrogênio $\left(\mathrm{H}^{+}\right)$com os quais o sal 2,3,5 trifenil cloreto de tetrazólio reage, formando um composto insolúvel e estável, de coloração avermelhada, denominado trifenilformazan (AOSA, 2009). A intensidade e localização das partes coloridas e descoloridas são utilizadas para a interpretação do teste. As sementes viáveis tendem a absorver a solução de tetrazólio lentamente, desenvolvendo coloração mais suave do que sementes deterioradas, que adquirem coloração rosa forte. Já para os tecidos mortos não há atividade dessas enzimas, portanto, sendo caracterizados pela coloração branca ou amarelados e textura flácida (FRANÇA NETO, 1999).

Alguns trabalhos têm evidenciado a eficiência do teste de tetrazólio em sementes de espécies arbóreas, como: Peltophorum dubium (OLIVEIRA; CARVALHO; DAVIDE, 2005); Tabebuia serratifolia e $T$. impetiginosa (OLIVEIRA, CARVALHO; NERY, 2005); Gleditschia amorphoides (FOGAÇA et al., 2006); Lafoensia pacari (MENDONÇA; COELHO; LUCHESE, 2006); Schizolobium parahyba (FERREIRA et al., 2007); Ocotea porosa (KALIL FILHO et al., 2008); Poecilanthe parviflora (PINTO et al., 2008); Melanoxylon brauna (CORTE, BORGES; PEREIRA, 2010); Copaifera langsdorffii e Schizolobium parahyba (FOGAÇA et al., 2011); Ceiba speciosa (LAZAROTTO et al., 2011). Nestes trabalhos são indicados procedimentos de pré-condicionamento para garantir a penetração da solução nos tecidos de interesse a serem avaliados; a utilização de diferentes concentrações 
da solução de tetrazólio, tempos e temperaturas de condicionamento e a avaliação adequada da coloração das sementes. Segundo Oliveira, Carvalho e Davide (2005), esses fatores são fundamentais para que se obtenha resultados confiáveis sobre a qualidade das sementes.

Dessa forma, o presente trabalho foi desenvolvido objetivando-se avaliar a eficiência do teste de tetrazólio para diferenciar o vigor em lotes de sementes de timbaúba.

\section{Material e Métodos}

O experimento foi conduzido no Laboratório de Análise de Sementes (LAS) do Departamento de Ciências Vegetais da Universidade Federal Rural do Semi-Árido (UFERSA), em Mossoró-RN (511' $\mathrm{S}$ e $37^{\circ} 20^{\prime} \mathrm{W}$ ), durante os meses de novembro a dezembro de 2012. Foram utilizados quatro lotes de sementes de timbaúba coletados em Mossoró RN nos anos de 2007 (lote 1), 2008 (lote 2), 2010 (lote 3) e 2012 (lote 4). Após a coleta, as sementes foram extraídas manualmente dos frutos, descartandose aquelas com orifícios ocasionados por insetos e má formação. Em seguida, as sementes foram acondicionadas em sacos de papel e armazenadas em ambiente controlado $\left(16-18{ }^{\circ} \mathrm{C}\right.$ e $40 \%$ de umidade relativa do ambiente) durante toda fase experimental.

Os quatro lotes de sementes de timbaúba foram submetidos às seguintes determinações e testes: a) teor de água - utilizou-se o método da estufa a 105 $\pm 3{ }^{\circ} \mathrm{C}$ por 24 horas com duas subamostras de 20 sementes e os resultados expressos em porcentagem (base úmida) (BRASIL, 2009); b) teste de germinação - conduzido com quatro repetições de 25 sementes para cada lote, escarificadas com lixa 80 (AZEREDO et al., 2003) e postas para germinar em bandejas de alumínio, tendo como substrato areia e mantidas à temperatura ambiente de laboratório $\left(25\right.$ a $\left.28{ }^{\circ} \mathrm{C}\right)$. As contagens das plântulas normais foram realizadas aos quinze dias após a semeadura (BRASIL, 2009); c) primeira contagem de germinação - realizada conjuntamente com o teste de germinação, avaliando-se a porcentagem de plântulas normais aos sete dias após a semeadura (BRASIL, 2009); d) velocidade de germinação realizado concomitante ao teste de germinação, sendo os dados utilizados para cálculo do índice coletados diariamente até o décimo quinto dia, seguindo-se metodologia recomendada por Edmond e Drapala (1958).

Os procedimentos gerais para a hidratação, o preparo e a coloração das sementes de timbaúba para o teste de tetrazólio foram definidos em testes preliminares (dados não apresentados). Inicialmente, as sementes foram lixadas no lado oposto ao embrião até pequena exposição dos cotilédones e posterior imersão em água por 24 horas, a $25{ }^{\circ} \mathrm{C}$. Em seguida, o tegumento foi cuidadosamente retirado, e as sementes colocadas em copos plásticos (quatro repetições com 25 sementes), sendo totalmente submersas em solução de 2,3,5 trifenil cloreto de tetrazólio, nas concentrações de 0,$1 ; 0,075$ e $0,050 \%$ e mantidas no escuro à temperatura de $35^{\circ} \mathrm{C}$, por períodos de 1 ; 3 e 6 horas. Decorridos estes períodos de coloração, as sementes foram lavadas em água corrente, seccionadas longitudinalmente no centro do eixo embrionário e avaliadas quanto à uniformidade e à intensidade de coloração apresentadas pelos tecidos, sendo classificadas em duas categorias: a) viáveis e b) não viáveis, de acordo com padrões indicados por Pinto et al (2008). Foram consideradas como viáveis as sementes com coloração rosa claro brilhante, tecidos com aspecto normal e firme, menos de $50 \%$ dos cotilédones descoloridos, cotilédones com regiões necrosadas, não afetando a região de ligação com o eixo embrionário e eixo embrionário com coloração vermelha intensa, porém, sem atingir o cilindro central. Como não viáveis, foram classificadas as sementes que apresentavam mais de $50 \%$ dos cotilédones descoloridos, com coloração vermelha intensa ou necrosada e, eixo embrionário com regiões descoloridas, vermelha intensa e/ou necrosada, atingindo o cilindro central. 
Os resultados foram expressos em porcentagem de sementes viáveis.

O experimento foi conduzido em delineamento estatístico inteiramente casualizado. Os resultados foram submetidos à análise de variância e as médias foram comparadas pelo teste Tukey em nível de 5\% de probabilidade, com o auxílio do programa estatístico Sistema para Análise de Variância SISVAR (FERREIRA, 2008) e posteriormente à análise de correlação de Pearson $(p<0,05)$.

\section{Resultados e Discussão}

A porcentagem de germinação, primeira contagem e velocidade de germinação das sementes do lote 4 foram superiores aos demais lotes testados. Quanto à primeira contagem e velocidade de germinação, os lotes 1,2 e 3 não diferiram estatisticamente, no entanto, para a germinação, os lotes 2 e 3 não diferiram estatisticamente, sendo superiores ao lote 1 (Tabela 1). A melhor qualidade verificada para o lote 4 pode ser atribuída ao fato deste ter sido recém-colhido, enquanto nos demais, mesmo armazenados em condições controladas, houve redução da qualidade fisiológica.

Tabela 1. Valores de teor de água (\%), germinação (\%), primeira contagem de germinação (\%) e velocidade de germinação (dias) de sementes de timbaúba (Enterolobium contortisiliquum (Vell.) Morong). Universidade Federal Rural do Semi-Árido, Mossoró, RN, 2013.

\begin{tabular}{ccccc}
\hline Lote & Teor de água & Germinação & Primeira contagem & Velocidade de germinação \\
\hline 1 & 7,7 & $51 \mathrm{c}$ & $22 \mathrm{~b}$ & $7,95 \mathrm{~b}$ \\
2 & 8,3 & $63 \mathrm{~b}$ & $28 \mathrm{~b}$ & $8,03 \mathrm{~b}$ \\
3 & 9,4 & $65 \mathrm{~b}$ & $33 \mathrm{~b}$ & $7,95 \mathrm{~b}$ \\
4 & 7,9 & $86 \mathrm{a}$ & $75 \mathrm{a}$ & $6,68 \mathrm{a}$ \\
\hline Média & - & 66 & 40 & 7,66 \\
CV $(\%)$ & - & 7,65 & 34,90 & 5,07 \\
\hline
\end{tabular}

*Médias seguidas pela mesma letra na coluna não diferem entre si pelo teste Tukey em nível de 5\% de probabilidade.

Fonte: Elaboração dos autores.

Para o teste de tetrazólio foram estabelecidas duas classes de sementes: 1) viáveis e 2) não viáveis (Figuras 1 e 2).

A exposição das sementes pelo período de uma hora, não conseguiu promover a separação dos lotes em diferentes níveis de vigor em nenhuma das concentrações estudadas (Tabela 2). Além disso, a tonalidade da coloração mostrou-se inadequada, assumindo um padrão muito claro, o que dificultou a interpretação dos resultados. 
Figura 1. Sementes viáveis de timbaúba (Enterolobium contortisiliquum (Vell.) Morong): embriões com coloração rosa e tecidos com aspecto normal e firme (A, B, C e D); cotilédones com regiões necrosadas não afetando a região de ligação com o eixo embrionário (D); eixo embrionário com coloração vermelha intensa, porém, sem atingir o cilindro central (E, F, G e H). Universidade Federal Rural do Semi-Árido, Mossoró, RN, 2013.
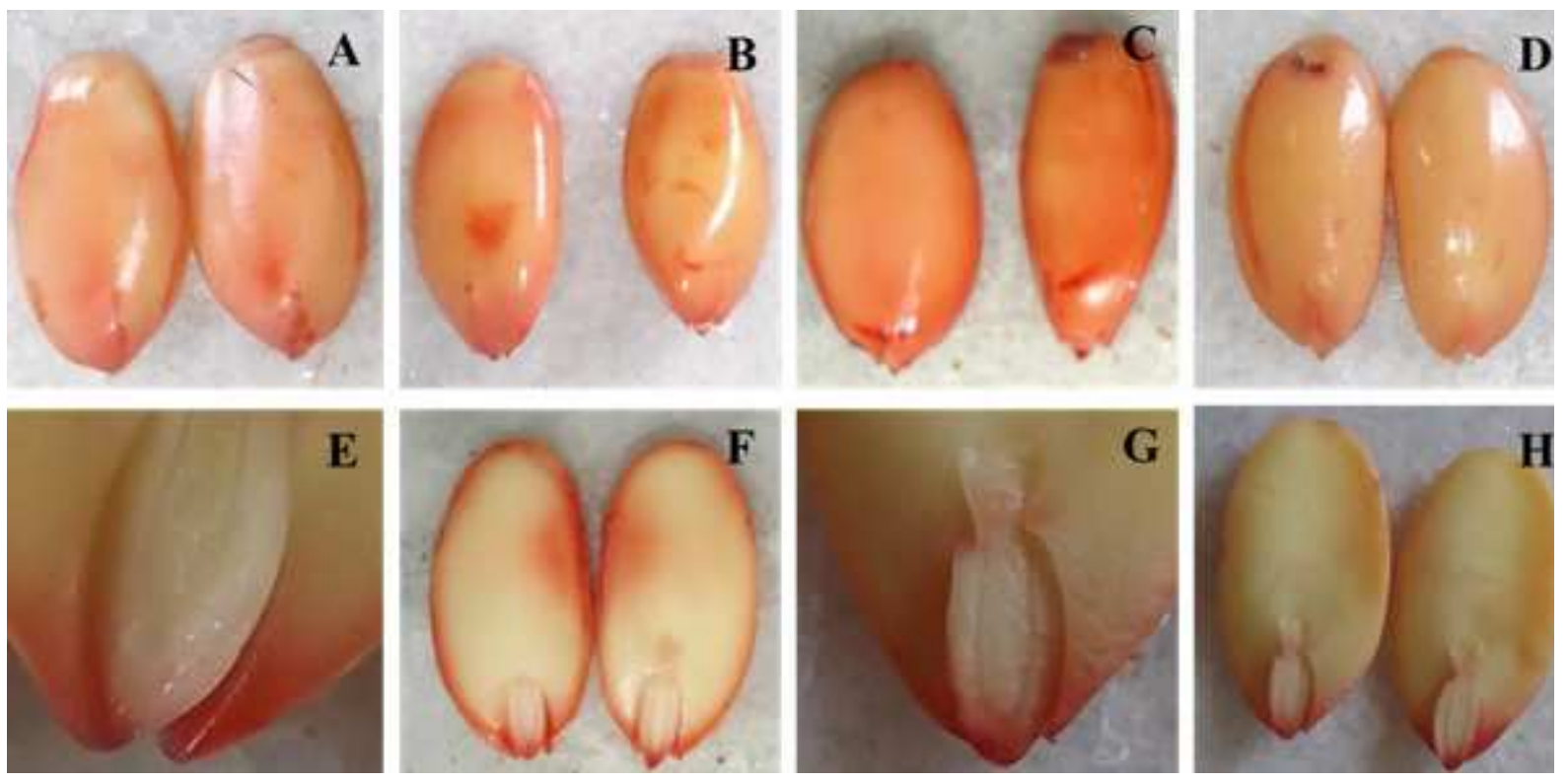

Fonte: Elaboração dos autores.

Figura 2. Sementes não viáveis de timbaúba (Enterolobium contortisiliquum (Vell.) Morong): embriões com mais de $50 \%$ dos cotilédones descoloridos, com coloração vermelha intensa ou necrosados ( $\mathrm{A}, \mathrm{B}, \mathrm{C}$ e $\mathrm{D})$; eixo embrionário com regiões descoloridas, vermelha intensa e/ou necrosada, atingindo o cilindro central (E, F, G e H). Universidade Federal Rural do Semi-Árido, Mossoró, RN, 2013.
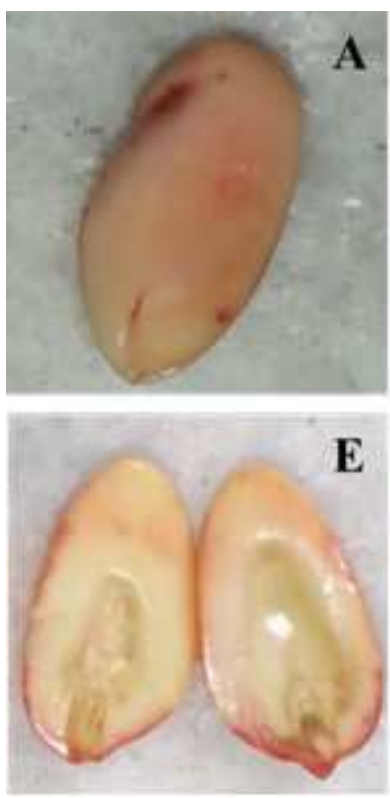

Fonte: Elaboração dos autores.
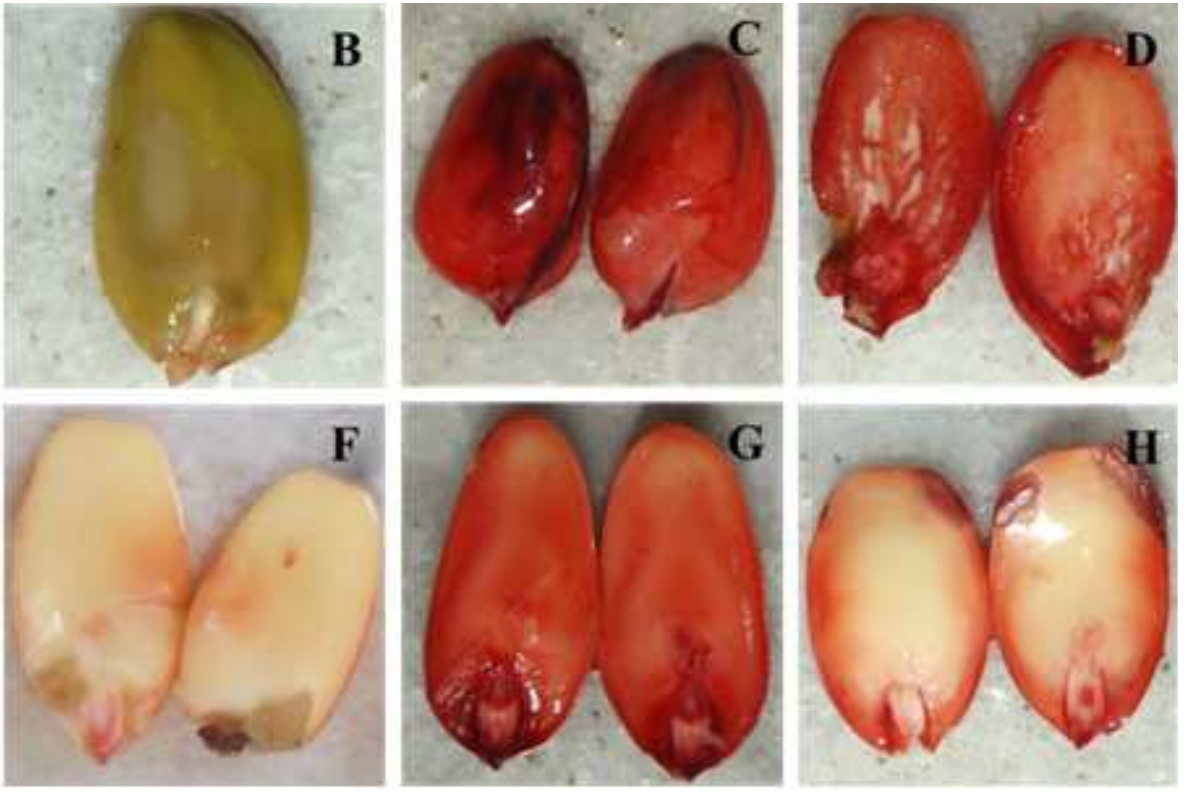
Tabela 2. Porcentagem de sementes viáveis de timbaúba (Enterolobium contortisiliquum (Vell.) Morong) obtidas pelo teste de tetrazólio, em diferentes combinações de tempo e concentrações. Universidade Federal Rural do Semi-Árido, Mossoró, RN, 2013.

\begin{tabular}{|c|c|c|c|c|c|c|c|c|c|}
\hline \multirow{2}{*}{ Lote } & \multicolumn{3}{|c|}{1 hora } & \multicolumn{3}{|c|}{3 horas } & \multicolumn{3}{|c|}{6 horas } \\
\hline & 0,100 & 0,075 & 0,050 & 0,100 & 0,075 & 0,050 & 0,100 & 0,075 & 0,050 \\
\hline 1 & $86 \mathrm{a}$ & $85 \mathrm{a}$ & $79 \mathrm{~b}$ & $71 \mathrm{a}$ & $63 \mathrm{c}$ & $69 \mathrm{c}$ & $35 \mathrm{a}$ & $34 \mathrm{c}$ & $75 \mathrm{~b}$ \\
\hline 2 & $90 \mathrm{a}$ & $93 \mathrm{a}$ & $90 \mathrm{ab}$ & $73 \mathrm{a}$ & $73 \mathrm{~b}$ & $75 \mathrm{bc}$ & $49 \mathrm{a}$ & $68 \mathrm{~b}$ & $53 \mathrm{c}$ \\
\hline 3 & $90 \mathrm{a}$ & $94 \mathrm{a}$ & $94 \mathrm{a}$ & $74 \mathrm{a}$ & $75 \mathrm{~b}$ & $80 \mathrm{~b}$ & $42 \mathrm{a}$ & $65 \mathrm{~b}$ & $59 \mathrm{bc}$ \\
\hline 4 & $93 \mathrm{a}$ & $95 \mathrm{a}$ & $91 \mathrm{ab}$ & $73 \mathrm{a}$ & $86 \mathrm{a}$ & 99 a & $46 \mathrm{a}$ & $93 \mathrm{a}$ & $98 \mathrm{a}$ \\
\hline Média & 89,69 & 91,56 & 88,44 & 72,50 & 74,06 & 80,63 & 42,81 & 64,69 & 70,94 \\
\hline CV (\%) & 3,86 & 7,01 & 7,34 & 13,43 & 4,28 & 5,52 & 17,92 & 13,15 & 14,78 \\
\hline
\end{tabular}

*Médias seguidas pela mesma letra na coluna não diferem entre si pelo teste Tukey em nível de 5\% de probabilidade.

Fonte: Elaboração dos autores.

A eficiência do teste tetrazólio em avaliar a viabilidade e vigor das sementes está relacionada ao desenvolvimento de metodologia adequada para cada espécie, de modo a definir as condições mais apropriadas para o preparo e o pré-condicionamento e coloração das sementes (BHERING; DIAS; BARROS, 2005). Segundo Delouche (2002), neste teste os danos fisiológicos e necroses nas sementes são mostrados em vívidos padrões de vermelho e branco (ou cor natural da semente), e ficam claramente evidentes os padrões e a natureza progressiva da deterioração.

A exposição das sementes à solução de tretrazólio pelo período de seis horas também não se mostrou adequada para a avaliação da viabilidade das sementes de timbaúba, não havendo diferença significativa entre os lotes na concentração de $0,1 \%$. Embora as menores concentrações da solução de tetrazólio $(0,05$ e $0,075 \%)$ tenham conseguido separar os lotes em diferentes níveis de vigor (Tabela 2) e a concentração de $0,075 \%$ tenha apresentado correlação positiva com a germinação (Tabela 3), houve uma grande divergência entre os valore obtidos no teste e os valores verificados no teste de germinação (Tabela 1).

Com relação ao padrão de coloração, o período de exposição de seis horas mostrou-se inadequado, uma vez que os embriões assumiram coloração vermelha muito intensa, o que pode levar a interpretação errônea dos resultados, levando a subestimação do vigor do lote. Outro fator negativo foi a coloração rósea que a solução de tetrazólio assumiu após a realização do teste, sugerindo que a exposição ocorreu por período superior ao necessário.

A condução do teste de tetrazólio pelo período de três horas mostrou-se como mais adequada. Não houve mudança de cor da solução e o padrão de coloração apresentado pelos embriões foi uniforme e de fácil interpretação. No entanto, a concentração de $0,1 \%$ não foi adequada para a realização do teste, não sendo verificada diferença estatística entre os lotes estudados (Tabela 2). A obtenção de coloração uniforme e adequada para a interpretação segura e eficiente é fator importante para o sucesso do uso do teste (BHERING; DIAS; BARROS, 2005).

A combinação mais adequada para a realização do teste de tetrazólio foi a exposição dos embriões pelo período de três horas nas menores concentrações $(0,05$ e $0,075 \%)$, havendo separação de lotes de forma adequada (Tabela 2) e com valores de viabilidade próximos aos verificados no teste de germinação (Tabela 1). 
Tabela 3. Coeficientes de correlação entre teste de tetrazólio, germinação, primeira contagem de germinação e velocidade de germinação em sementes de timbaúba (Enterolobium contortisiliquum (Vell.) Morong). Universidade Federal Rural do Semi-Árido, Mossoró, RN, 2013.

\begin{tabular}{ccccc}
\hline Tempo de & Concentração & \multicolumn{3}{c}{ Correlação } \\
\cline { 3 - 5 } embebição $(\mathrm{h})$ & $(\%)$ & Germinação & Primeira contagem & Velocidade de germinação \\
\hline \multirow{2}{*}{1} & 0,100 & 0,545 & 0,711 & $-0,731$ \\
& 0,075 & 0,831 & 0,650 & $-0,507$ \\
& 0,050 & 0,669 & 0,453 & $-0,284$ \\
\hline \multirow{2}{*}{3} & 0,100 & 0,383 & 0,170 & 0,016 \\
& 0,075 & $0,990^{* *}$ & $0,918^{*}$ & $-0,834$ \\
\hline \multirow{2}{*}{6} & 0,050 & $0,988^{* *}$ & $0,985^{* *}$ & $-0,935^{*}$ \\
\hline & 0,100 & 0,646 & 0,458 & $-0,378$ \\
& 0,075 & $0,965^{*}$ & 0,859 & $-0,771$ \\
\hline
\end{tabular}

**Significativo em nível de $1 \%$ de probabilidade de erro pelo teste de Tukey.

*Significativo em nível de $5 \%$ de probabilidade de erro pelo teste de Tukey.

Fonte: Elaboração dos autores.

Geralmente, os resultados do teste de tetrazólio aproximam-se do teste de germinação ou os valores obtidos no teste de tetrazólio são maiores. Segundo Oliveira, Carvalho e Davide (2005), isso acontece porque no teste de tetrazólio somente o embrião é avaliado, não considerando a influência das estruturas externas das sementes nos resultados dos testes de germinação, como a possíveis infestações com patógenos no lote.

Segundo Ferreira, Davide e Motta (2004), os resultados dos testes de germinação e de tetrazólio devem ser semelhantes, com pequena margem de diferença entre eles. Embora a concentração de $0,075 \%$, diferentemente da concentração de $0,05 \%$, não tenha apresentado correlação positiva com a velocidade de germinação (Tabela 3), os resultados do teste de tetrazólio nesta concentração foram os que mais se aproximaram dos obtidos no teste de germinação.

A metodologia de condução do teste de tetrazólio apresenta variações em função da espécie em estudo. Em geral, para a coloração adequada de espécies florestais são necessárias altas concentrações da solução de tetrazólio, a exemplo de $0,3 \%$ para Melanoxylon brauna (CORTE, BORGES; PEREIRA, 2010) e 0,5\% para Tabebuia serratifolia (OLIVEIRA; CARVALHO; NERY, 2005), Schizolobium parahyba (FERREIRA et al., 2007) e Ceiba speciosa (LAZAROTTO et al., 2011). No entanto, assim como no caso dos resultados obtidos neste estudo, algumas espécies reagem a concentrações mais baixas, como em estudos realizados por Pinto et al. (2008), com Poecilanthe parviflora, onde a eficiência do teste foi verificada quando conduzido em solução de 0,075\%, por 90 minutos e por Oliveira, Carvalho e Nery (2005), com Tabebuia impetiginosa, com melhores resultados obtidos com a concentração de $0,070 \%$, por 12 horas.

O teste de tetrazólio é uma alternativa viável para a avaliação da viabilidade de sementes de timbaúba. Para condução do teste recomenda-se a escarificação das sementes seguida de embebição por 24 horas e retirada do tegumento, com posterior imersão das sementes em solução de tetrazólio a $0,075 \%$, por três horas, a $35{ }^{\circ} \mathrm{C}$, temperatura usada no presente trabalho. 


\section{Referências}

ALEXANDRE, R. S.; GONÇALVES, F. G.; ROCHA, A. P.; ARRUDA, M. P.; LEMES, E. Q. Tratamentos físicos e químicos na superação de dormência em sementes de Enterolobium contortisiliquum (Vell.) Morong. Revista Brasileira de Ciências Agrárias, Recife, v. 4, n. 2, p. 156159, 2009.

ARAÚJO, A. P.; PAIVA SOBRINHO, S. Germinação e produção de mudas de tamboril (Enterolobium Contortisiliquum (Vell.) Morong) em diferentes substratos. Revista Árvore, Viçosa, v. 35, n. 3, p. 581588, 2011.

ASSOCIATION OF OFFICIAL SEED ANALYSTS AOSA. Seed vigour testing handbook. East Lansing: AOSA, 2009. 334 p. (Contribution, 32).

AZEREDO, G. A.; BRUNO, R. L. A.; ANDRADE, L. A.; CUNHA, A. O. Germinação em sementes de espécies florestais da mata atlântica (leguminoseae) sob condições de casa de vegetação. Pesquisa Agropecuária Tropical, Goiânia, v. 33, n. 1, p. 11-16, 2003.

BHERING, M. C.; DIAS, D. C. F. S.; BARROS, D. I. Adequação da metodologia do teste de tetrazólio para avaliação da qualidade fisiológica de sementes de melancia. Revista Brasileira de Sementes, Londrina, v. 27, n. 2, p. 176-182, 2005.

BRASIL. Ministério da Agricultura, Pecuária e Abastecimento. Regras para análise de sementes. Ministério da Agricultura, Pecuária e Abastecimento. Secretaria de Defesa Agropecuária. Brasília: MAPA/ ACS, 2009. 395 p.

CORTE, V. B.; BORGES, E. E. L.; PEREIRA, B. L. C. Adequação da metodologia do teste de tetrazólio para avaliação da viabilidade de sementes de Melanoxylon brauna Schot. Cerne, Lavras, v. 16, n. 3, p. 415-421, 2010.

COSTA, C. J.; SANTOS, C. P. Teste de tetrazólio em sementes de leucena. Revista Brasileira de Sementes, Lavras, v. 32, n. 2, p. 66-72, 2010.

COSTA, M. S.; ALVES, S. M. C.; FERREIRA NETO, M.; BATISTA, R. O.; COSTA, L. L. B.; OLIVEIRA, W. M. Produção de mudas de timbaúba sob diferentes concentrações de efluente doméstico tratado. Irriga, Botucatu, v. 1, n. 1, p. 408-422, 2012. Edição Especial.

COSTA, R. L. D.; MARINI, A.; TANAKA, D.; BERNDT, A.; ANDRADE, F. M. E. Um caso de intoxicação de bovinos por Enterolobium contortisiliquum (timboril) no Brasil. Revista Archivos de Zootecnia, Córdoba, n. 58, v. 2, p. 313-316, 2009.

DELOUCHE, J. C. Germinação, deterioração e vigor da semente. Seed News, Pelotas, v. 6, n. 6, p. 45-48, 2002.

EDMOND, J. B.; DRAPALA, W. J. The effects of temperature, sand, soil, and acetone on germination of okra seeds. Proceedings of the American Society for Horticultural Science, Geneva, v. 71, n. 5, p. 428-434, 1958.

FERREIRA, D. F. Sisvar: um programa para análises e ensino de estatística. Revista Symposium, Recife, v. 6, n. 2, p. 36-41, 2008.

FERREIRA, R. A.; DAVIDE, A. C.; MOTTA, M. S. Vigor e viabilidade de sementes de Senna multijuga (Rich.) Irwin et Barn.e Senna macranthera (Collad.) Irwin et Barn., num banco de sementes em solo de viveiro. Revista Brasileira de Sementes, Londrina, v. 26, n. 1, p. 24-31, 2004.

FERREIRA, R. A.; OLIVEIRA, L. M.; TONETTI, A. O. O; DAVIDE, A. C. Comparação da viabilidade de sementes de Schizolobium parahyba (Vell.) Blake - Leguminosae Caesalpinioideae, pelos testes de germinação e tetrazólio. Revista Brasileira de Sementes, Londrina, v. 29, n. 3, p. 83-89, 2007.

FOGAÇA, C. A.; KROHN, N. G.; SOUZA, M. A.; PAULA, R. C. Teste de tetrazólio em sementes de Copaifera langsdorffii e Schizolobium parahyba. Floresta, Curitiba, v. 41, n. 4, p. 895-904, 2011.

FOGAÇA, C. A.; MALAVASI, M. M.; ZUCARELI, C.; MALAVASI, U. C. Aplicação do teste de tetrazólio em sementes de Gleditschia amorphoides Taub. Caesalpinaceae. Revista Brasileira de Sementes, Londrina, v. 28, n. 3, p. 101-107 2006.

FRANÇA NETO, J. B. Testes de tetrazólio para determinação do vigor de sementes. In: KRZYZANOWSKI, F. C.; VIEIRA, R. D.; FRANÇA NETO, J. B. (Ed.). Vigor de sementes: conceitos e testes. Londrina: ABRATES, 1999. cap. 8, p. 1-7.

KALIL FILHO, A. N.; LOPES, A. J.; RÊGO, G. M.; TOMACHITZ, A. Avaliação da qualidade fisiológica de sementes de imbuia pelo teste do tetrazólio. Pesquisa Florestal Brasileira, Colombo, v. único, n. 57, p. 69-72, 2008.

LARRÉ, C. F.; MORAES, D. M.; LOPES, N. F. Potencial fisiológico de dois lotes de sementes de arroz tratadas com 24-epibrassinolídeo. Revista Brasileira de Sementes, Londrina, v. 31, n. 4, p. 27-35, 2009.

LAZAROTTO, M.; PIVETA, G.; MUNIZ, M. F. B.; REJANE, L.; REINIGER, S. Adequação do teste de tetrazólio para avaliação da qualidade de sementes de Ceiba speciosa. Semina: Ciências Agrárias, Londrina, v. 32, n. 4, p. 1243-1250, 2011. 
LIMA, R. S.; OLIVEIRA, P. L.; RODRIGUES, L. R. Anatomia do lenho de Enterolobium contortisiliquum (Vell.) Morong (Leguminosae-Mimosoideae) ocorrente em dois ambientes. Revista Brasileira de Botânica, São Paulo, v. 32, n. 2, p. 361-374, 2009.

LORENZI, H. Árvores brasileiras: manual de identificação e cultivo de plantas arbóreas nativas do Brasil. 4. ed. Nova Odessa: Instituto Plantarum, 2002. $384 \mathrm{p}$.

MENDONÇA, E. A. F.; COELHO, M. F. B.; LUCHESE, M. Teste de tetrazólio em sementes de mangaba-brava (Lafoensia pacari St.-Hil. - Lythraceae). Revista Brasileira de Plantas Medicinais, Botucatu, v. 8, n. 2, p. 33-38, 2006.
OLIVEIRA, L. M.; CARVALHO, M. L. M.; DAVIDE, A. C. Teste de tetrazólio para avaliação da qualidade de sementes de Peltophorum dubium (Sprengel) Taubert Leguminosae Caesalpinioideae. Cerne, Lavras, v. 11, n. 2, p. 159-166, 2005.

OLIVEIRA, L. M.; CARVALHO, M. L. M.; NERY, M. C. Teste de tetrazólio em sementes de Tabebuia serratifolia Vahl Nich. e T. impetiginosa (Martius ex A. P. de Candolle) Standley - Bignoniaceae. Revista Ciência Agronômica, Fortaleza, v. 36, n. 2, p. 169-174, 2005.

PINTO, T. L. F.; BRANCALION, P. H. S.; NOVEMBRE, A. D. L. C. N.; CICERO, S. M. Avaliação da viabilidade de sementes de coração-de-negro (Poecilanthe parviflora Benth. - Fabaceae-Faboideae) pelo teste de tetrazólio. Revista Brasileira de Sementes, Londrina, v. 30, n. 1, p. 208-214, 2008. 
